Jut 0 :

\title{
COMPARISON OF SYNCHROTRON X-RAY MICROANALYSIS WITH \\ ELECTRON AND PROTON MICROSCOPY FOR INDIVIDUAL PARTICLE ANALYSIS
}

K. H. Janssens, F. van Langevelde, F. C. Adams

University of Antwerp (U.I.A.), B-2610 Wilrijk/Antwerp, Belgium

R. D. Vis

Free University of Amsterdam, 1007 MC Amsterdam, The Netherlands

S. R. Sutton, M. L. Rivers

The University of Chicago, Chicago, Illinois 60637 USA

K. W. Jones

Brookhaven National Laboratory, Upton, New York 11973 USA

D. K. Bowen

University of Warwick, Coventry CV4 7AL, Great Britain

Presented at

Pacific-International Congress on X-Ray Analytical Methods (PIXCAM)

Honolulu, Hawaii

August 9-18, 1991

By acceptance of this article, the publisher and/or recipient acknowledges the US Government's right to retain a nonexclusive, royalty-free license in and to any copyright covering this paper.

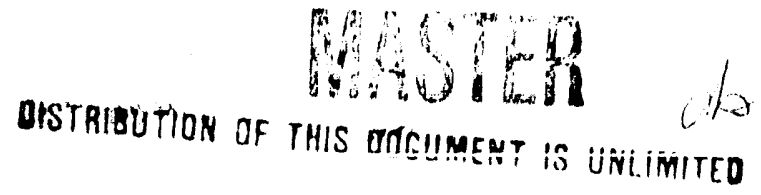


COMPARISON OF SYNCHROTRON X-RAY MICROANALYSIS WITH ELECTRON AND PROTON

MICROSCOPY FOR INDIVIDUAL PARTICLE ANALYSIS

K.H. Janssens ${ }^{1}$, E. van Langevelde', F.C. Adams ${ }^{1}$, R.D. Vis ${ }^{2}$, S.R. Sutton ${ }^{3}$, M.I. Rivers ${ }^{3}$, K.W. Jones ${ }^{3}$ and D.K. Bowen 4

${ }^{1}$ Department of Chemistry, University of Antwerp (U.I.A.), Universiteitsplein 1, B-2610 Wilrijk/Antwerp, Belgium

${ }^{2}$ Department of Physics and Astronomy, Free University of Amsterdam, P.0. Box 7161, 1007 MC Amsterdam, The Netherlands ${ }^{3}$ Department of Applied Science, Brookhaven National Laboratories, Upton, NY 11973, USA

${ }^{4}$ Department of Electrical Engineering, University of Warwick, Coventry CV4 7AL, Great Britain

INTRODUCTION

A considerable number of the elements and a profusion of organic compounds are emitted into the atmosphere in association with solid and liquid particles. More than 50 percent of all air pollutants are preferentially present in particulate matter rather than in the gas phase. The assessment of the potential environmental and toxic effects of particulate matter in the atmosphere requires a detailed physical and chemical characterization. Methods for analyzing aerosols have recently been extengively reviewed by Maenhaut. Most of these techniques are trace-level bulk analytical methods such as ICP-MS (Inductively Coupled plasma Mass Spectrometry) ${ }^{2}$, AAS (Atomic Absorption spectrometry) and its variations ${ }^{3}$, INAA (Instrumental Neutron Activation Analysis)", (macro-)PIXs ${ }^{5}$ (Particle Induced $X$-ray Emission; and conventional X-ray Fluorescence (XRF) ${ }^{6}$.

An overview of techniques for the analysis of individual airborne particles is given in the book by spurny? ${ }^{7}$. Such techniques include EPMA ${ }^{8}$ (Electron Probe Micro Analysis), micro-PIXE ${ }^{9}$ and LAMMA ${ }^{10}$ (Laser Mass Micro Analysis). By analyzing particles individually, after a classification step, the contributions and composition of each particle source at the sampling location (e.g., sea spray, soil dust, car exhaust, industrial fumes) can be determined directly. In this respect, charged particle-beam techniques such as EPMA have the obvious advantage that particle localization and data acquisition can be automated ${ }^{8}$. EPMA (and for the higher $z$ elements also $\mu-$ PIXE), however, are limited in sensitivity. Due to the high bremsstrahlung background in electron induced $x$-ray spectra, EPMA features minimum detection limits (MDL's) in the 0.18 range. A drawback of the nuclear microprobe is the considerable energy deposition in the sample, especially when non-thin target materials are employed ${ }^{11}$.

Due to the high intensity of synchrotron radiation sources, yielding an increased sensitivity of analysis, and the high degree of polarisation of the radiation, causing a decrease in scattered background levels, sub-ppm detection limits for bulk analysis have been reported for synchrotron radiation induced X-ray fluorescence (SRXRF) 12-16. In most of these studies, comparisons were made with other $x$-ray emission techniques for bulk 
analys1s, such as PIXE14,13, tubo13,14- and rad10-1sotope exc1ted EDXRF'6,17. Relatively few $x$-ray microprobe facilities currently exist in the world. At Hasylab (Hamburg, FRG) and at the NSLS (Brookhaven, Upton, NY, USA), white light microprobes are in operation, using collimated pencil. beams and attaining lateral resolutions in the order of 3 to $10 \mu \mathrm{m}^{18,19} \mathrm{with}$ detection limits at the $10 \mathrm{ppm}$ level. At SRS ${ }^{20}$ (Daresbury, UK), SSRL ${ }^{21}$ (Stanford, $C A$ ) and the photon Factory 22 (Tsukuba, Japan), focused monochromatic microbeams are employed.

This paper is concerned with the evaluation of the use of $\mu-S R X R F$ as implemented at two existing $x$-ray microprobes for the analysis of individual particles. As representative environmental particulates, National Institutes of Science and Technology (NIST) K227, K309, K441 and K961 glass microspheres were analyzed using two types of $x$-ray micro probes: the white light microprobe at beamline X26A of the NSLS and the monochromatic (15 keV) $x$-ray microprobe at station 7.6 of the SRS. For reference, the particles were also analyzed with microanalytical techniques more commonly employed for individual particles analysis such as EPMA and micro-PIXE.

Evaluation of any microanalytical technique obviously involves assessing its sensitivity/limits of detection and its lateral resolution. Sensitive methods have the advantage that classification of particles can be done also on the basis of the trace element content of the particulates, making it possible to distinguish between two very similar aerosol sources. with respect to particle analysis, the lateral resolution is only important in the sense that particulates which are physically separated on a filter can also be analyzed separately. A much more important property of techniques suitable for individual particle analysis is the time required to obtain statistically meaningful information from each particle. This length of time obviously includes the data acquisition period (typically in the order of 20 to 100 sec/particle), but also entails the time required to locate and optimise the position of the next particle in the beam. As in atmospheric studies, in order to study, e.g., seasonal or regional variations in the aerosol composition, extensive numbers of samples are examined, while for each sample, several hundred of particles need to be analyzed, in practice, this property proves to be a very stringent one indeed.

For the four particle types and using the various microanalytical techniques mentioned above, $x$-ray spectra were collected from particles 20 to $30 \mathrm{\mu m}$ in size in order to compare attainable detection limits and typical analysis times. Using the white light $x$-ray microprobe and the electron microprobe, also the size dependence of the fluorescent $x-r a y$ yield was experimentally determined.

\section{EXPER IMENTAL}

\section{Sample material and sample preparation}

As representative examples of coarse mode environmental samples with known composition, NIST K227, K309, K441 and K961 glass microspheres were studied. Details on the preparation of these microspheres can be found in Ref. 23; the diameters of the spheres are in the range from 0.25 to $250 \mu \mathrm{m}$ (corresponding to a weight range of $20 \mathrm{fg}$ to $20 \mu \mathrm{\mu g} / \mathrm{particle}$ ) and were verified to be homogeneous and identical in composition to the bulk glass they were produced from using electron- and ion microscopy. The nominal composition of the various materials is listed in Table 1.

For the EPMA measurements, samples were prepared by dispersing the glass particles into an inert solvent ( $n$-hexane) and filtering through a polycarbonate filter with pore holes of $0.4 \mu \mathrm{m}$. The particles were 
Table 1. Nominal Composition of NIST glass microspheres.

\begin{tabular}{|c|c|c|c|c|}
\hline \multirow{2}{*}{ Element } & \multicolumn{4}{|c|}{ Concentration ( $z w)$} \\
\hline & 1.227 & K309 & K411 & K961 \\
\hline 0 & 16.4 & 38.82 & 42.88 & 47.00 \\
\hline $\mathrm{Na}$ & - & - & - & 2.97 \\
\hline $\mathrm{Mg}$ & - & - & 9.05 & 3.02 \\
\hline Al & - & 7.94 & - & 5.82 \\
\hline Si & 9.3 & 18.70 & 25.71 & 29.98 \\
\hline$P$ & - & - & - & 0.22 \\
\hline $\mathrm{K}$ & - & - & - & 2.49 \\
\hline $\mathrm{Ca}$ & - & 10.72 & 10.70 & 3.57 \\
\hline $\mathrm{Ti}$ & - & - & - & 1.20 \\
\hline$M n$ & - & - & - & 0.32 \\
\hline $\mathrm{Fe}$ & - & 10.49 & 11.66 & 3.50 \\
\hline $\mathrm{Ba}$ & - & 13.43 & - & - \\
\hline $\mathrm{Pb}$ & 74.3 & - & - & - \\
\hline
\end{tabular}

subsequently transferred onto marked electron microscopy grids coated with a formvar foil by pressing the grids against the filter. For the NSIS measurements, individual glass particles in the range 5 to 50 um were mounted onto Kapton foil through micro-manipulation and held in place by means of droplets of silicon-oil. The kapton foil was attached to cardboard $5 \mathrm{~mm}$ slide frames which fit into the micro probe sample holder. For the SRS and PIXE experiments, glass spheres were dispersed into a 2 of formvar solution: by means of a rotating disk, droplets of the suspension were spread out and allowed to dry in the form of thin films. These films were subsequently mounted onto Al support rings fitting in the sample holder of the microprobes.

\section{Instrumentation and Experimental Procedure}

For the white light syrichrotron excitation experiments, the $x-r a y$ microprobe at the $\times 26 \mathrm{~A}$ beamline of the NSLS (National synchrotron Light Sourcel was employed. After emerging from the storage ring UHV, the beam is defined by four $\mathrm{Ta}$ slits and further collimated by a $5 \times 8 \mathrm{\mu m}^{2}$ crossed slit system. The sample is positioned at $45^{\circ}$ to the incoming beam; $x$-ray spectra are detected using a Si(Li) detector positioned at 90 degrees to the original beam.

The spectrum impinging on the sample is shown in Fig. 1, having a maximum in flux density of about $10^{4}$ photons/sec/mA $/ \mu \mathrm{m}^{2}$ near $8 \mathrm{keV}$. Soft $\mathrm{x}-\mathrm{rays}$ (1) $<E<5 \mathrm{keV}$ ) are heavily absorbed in the Be-end window of the beam pipe and in the aif path between the collimator slits and the sample. Specimen can

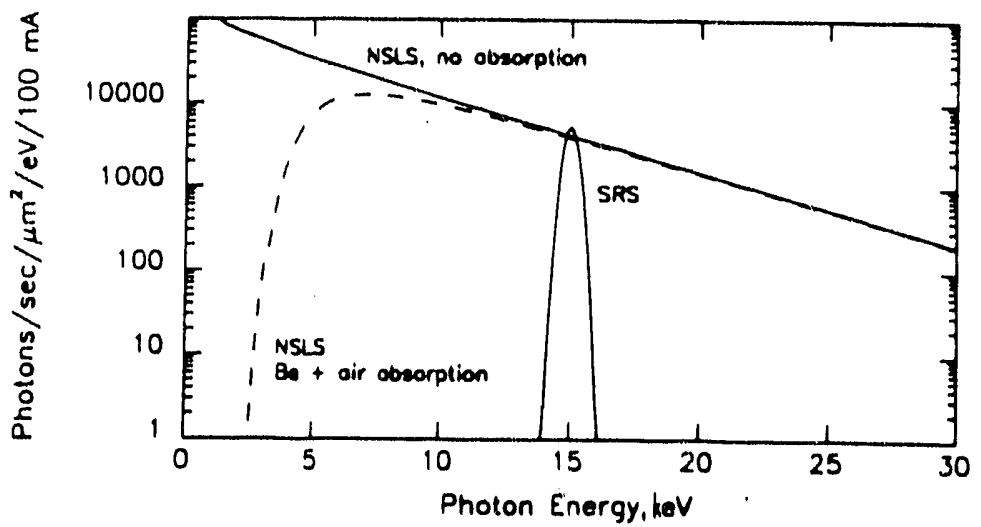

Fig. 1. Excitation Spectra at the NSLS and SRS XRM facilities. 
be viewed by a horizontally mounted stereozoom binocular microscope, equipped with a TV camera. X-ray spectra of the particles were collected by localising the particles on the foil using the microscope, moving them into the beam and maximizing the detectable count rate.

Experiments using monochromatic synchrotron radiation excitation were performed at station 7.6 of the synchrotron Radiation Source (SRS), Daresbury (UK). White radiation from the bending magnet beam line 7 was used as primary source for the measurements. The basic component of the microprobe is an ellipsoidaliy concave bent si(111) crystal which simultaneously monochromates and focuses $15 \mathrm{keV}$ radiation. The crystal passes a bandwidth of ca. $0.3 \mathrm{keV}$ and produces a focused beam spot of $10 \times 15$ $\mu \mathrm{m}^{2}$ FWHM; in the spot, flux densities of $3.410^{4} \mathrm{ph} / \mathrm{s} / \mathrm{mA} / \mu \mathrm{m}^{2}$ art achieved. A $50 \mathrm{~mm}^{2}$ area $S i(L i)$ detector is located at $90^{\circ}$ to the incoming beam at 35 $\mathrm{mm}$ from the sample. The sample is observed by means of a zeiss Sv 8 stereo (zoom) microscope with $175 \mathrm{~mm}$ working distance, equipped with a CCD camera. Details on the optics, beam profiles and fluxes can be found elsewhere ${ }^{20}$. The excitation spectrum of the SRS microprobe is also shown in Fig. $1 . S R$ induced $X$-ray spectra were obtained in a similar way as at the NSIS.

Micro-PIXE measurements were performed at the Nuclear Microprobe setup of the Free University, Amsterdam. $3 \mathrm{MeV}$ protons are accelerated by a Philips AVF cyclotron, yielding after focusing a microbeam of typically $2 \times 5$ $\mu \mathrm{m}^{2}$ cross section at the focal spot ${ }^{27}$, with a current density of 2 to 5 $\mathrm{pA} / \mu^{2}$. Similarly prepared samples as employed for the SRS measurements were used.

Using a Jeol 733B Superprobe microanalyser equipped with a Tracor TN2000 computer system, electron induced $X$-ray spectra were acquired for typically 120 sec per particles; data acquisition was started after manual localisation of the particles and focusing of the beam at their centre. A $25 \mathrm{kV}, 1 \mathrm{nA}$ electron beam was used in all cases.

RESULTS AND DISCUSSION

Peak-to-Background ratios and Limits of Detection

Eig. 2 shows $x$-ray spectra obtained from $k 961$ particles of 20 to $30 \mu$ diameter using resp. the white and monochromatic $x$-ray microprobes and the electron and protron microprobes. As can be seen from $F i g .2 a$, due to scattering of the white spectrum of the NSLS-microprobe, a more or less uniform background level of about 100 counts can be observed over the entire energy range for a collection time of 300 sec. In contrast, in the SRSspectrum (Fig. 2b), almost no background in the region $2-14 \mathrm{keV}$ is present. Only near $15 \mathrm{keV}$, the background level rises due to the low-energy tail of the incoherent scatter peak. As a results of the high count rates achievable at the NSLS facility, in Fig. 2 a also Ca+Fe and Fe+Fe sum peaks can be readily observed near 8 and $10 \mathrm{keV}$. Because the measurements are performed in air, also an appreciable Ar peak is present. The si characteristic radiation is heavily absorbed; no Al peak can be discerned. Fig. 2C illustrates the (dis) advantages of electron induced $x$-ray emission. Overall, a fairly high bremstrahlungs background is observed, although on the other hand, significant amounts of characteristic radiation of low-z elements such as $\mathrm{Na}, \mathrm{Mg}, \mathrm{Al}$ and $\mathrm{Si}$ can be detected in a relatively short counting time, which is not the case for the XRM measurements. It should be noted however that none of the XRM-instruments are optimized for light element detection (detector windows, air operation) and that the comparison is only valid for the specific conditions listed above. Finally, in Fig. 2d, the background due to proton-induced secondary electron bremsstrahlung only gives rise to an appreciable background in the 2-5 keV energy range.

To allow for a more quantitative comparison, Table 2 lists for the four microprobes the overall count rates and peak-to-background ratio's derived from the spectra in Fig. 2. For Mn and Fe, the SRS microprobe features the highest peak-to-background ratios, although for the lower elements, the NSIS 
micro probes offers better values. Despite the use of white light, the overall ratio of characteristic to background count rate is better for the NSLS than for the SRS case; the count rate is also a factor 100 higher at the NSIS than at Daresbury due to the differences in available flux at both facilities. For this type and size of particles, practical counting times per particle are in the range of 100 sec for the NSIS and 1000 sec for the SRS microprobe; for EPMA, typical counting times are shorter than 60 sec./particle. of the four techniques used, the PIXE spectra offer the best overall net-to-background ratio; however, due to the transparency of the microspheres to the proton beam and the fact that the beam current had to be limited to $25 \mathrm{pA}$ in view of sample charging, an acquisition time of 30 min./particle was required in order to obtain statistically meaningful spectra.

Employing as figure-of-merit the minimum limit of detection (IUPAC definition ${ }^{25}$ ) rather that the peak-to-background ratio, Fig. 3 shows MDI's for the four techniques as a function of the atomic number 2 . Whereas for EPMA, a more or less uniform sensitivity in the 100 ppm range is obtained, the MDL values of the other techniques vary considerable with atomic number. Corresponding to the maximum in the excitation spectrum of the NSLS XRM near $8 \mathrm{keV}$, the lowest $\mathrm{MDL}$ values are obtained for elements such as $\mathrm{Mn}$, Fe and Co. Here for $\mathrm{Fe}$, a relative $\mathrm{MDI}$ of $6 \mathrm{ppm}$ at a counting time of $100 \mathrm{sec}$. is achieved, corresponding in the present case to an absolute detectable amount of $7.8 \mathrm{fg}$ of $\mathrm{Fe}$. In the case of the SRS microprobe, an MDL for Fe of around $60 \mathrm{ppm}$ is obtained; for $\mathrm{zn}$, this value is expected to be around $5 \mathrm{ppm}$.
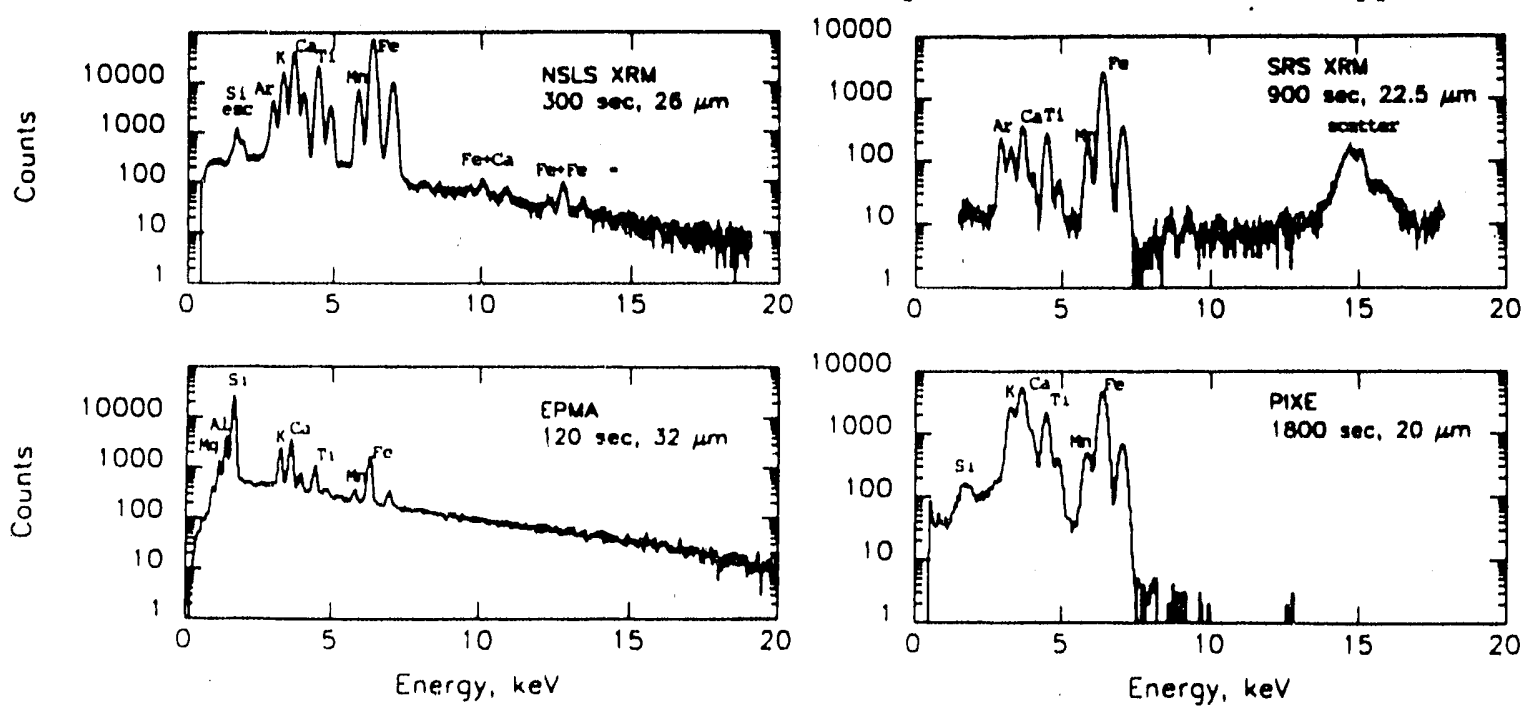

Fig. 2. X-ray spectra obtained from K961 glass microspheres using the four different micro probes.

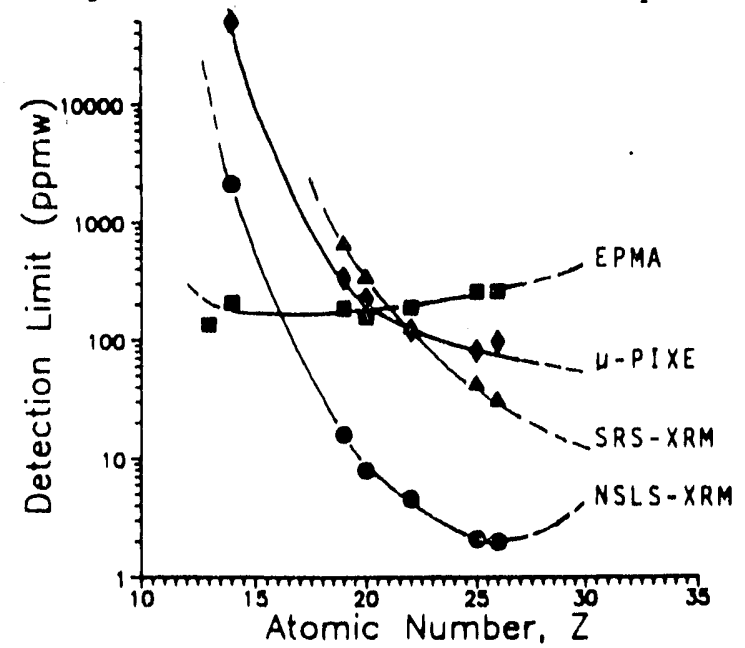

Eig. 3. Minimum Detection Limits obtainable using the four micro-probes at $100 \mathrm{sec}$ counting times in $K 309$ glass microspheres of 20-30 $\mu$ diameter. 
Table 2. Overall count rates and peak-to-background ratios derlved from the K961 particle spectra shown in Fig. 2.

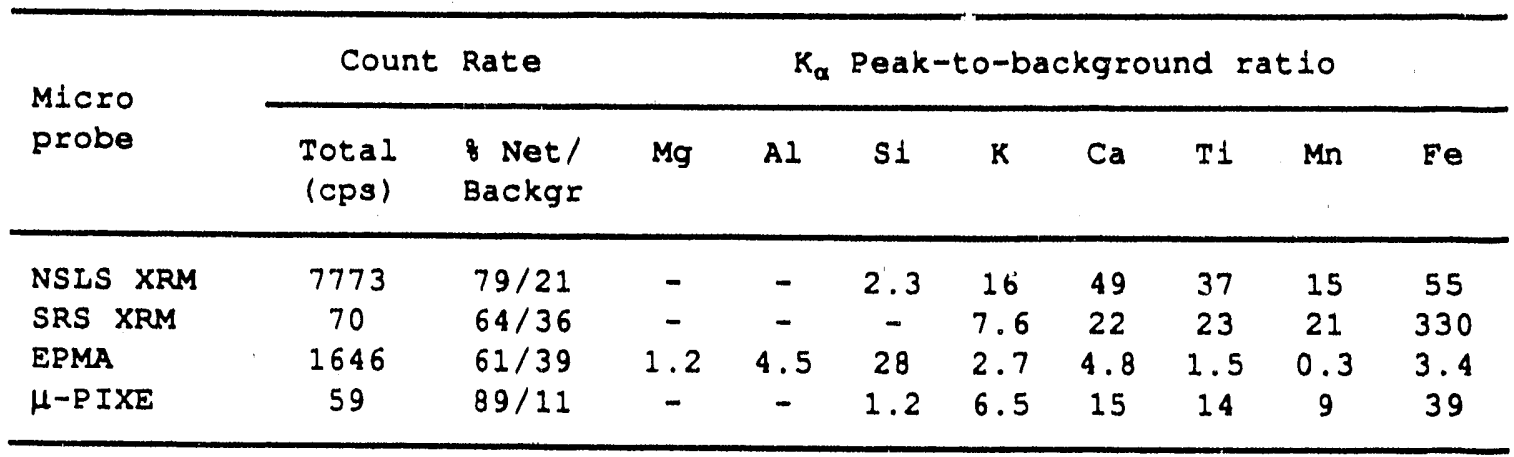

\section{Size dependence of $x$-ray yields}

As a function of particle diameter, $\mathrm{K} 961$ particles were analyzed using the NSLS XRM and the electron micro probe. The variation of the characteristic $x-r a y$ intensities with size is shown in Fig. 4. As the currently achievable synchrotron beam sizes are in the order of 5 to $10 \mu \mathrm{m}$, the optical resolution of the sample viewing microcope at the NSLS facility is also of this other. Consequently, only particles with radid down to 3.5 $\mu m$ could be analyzed.
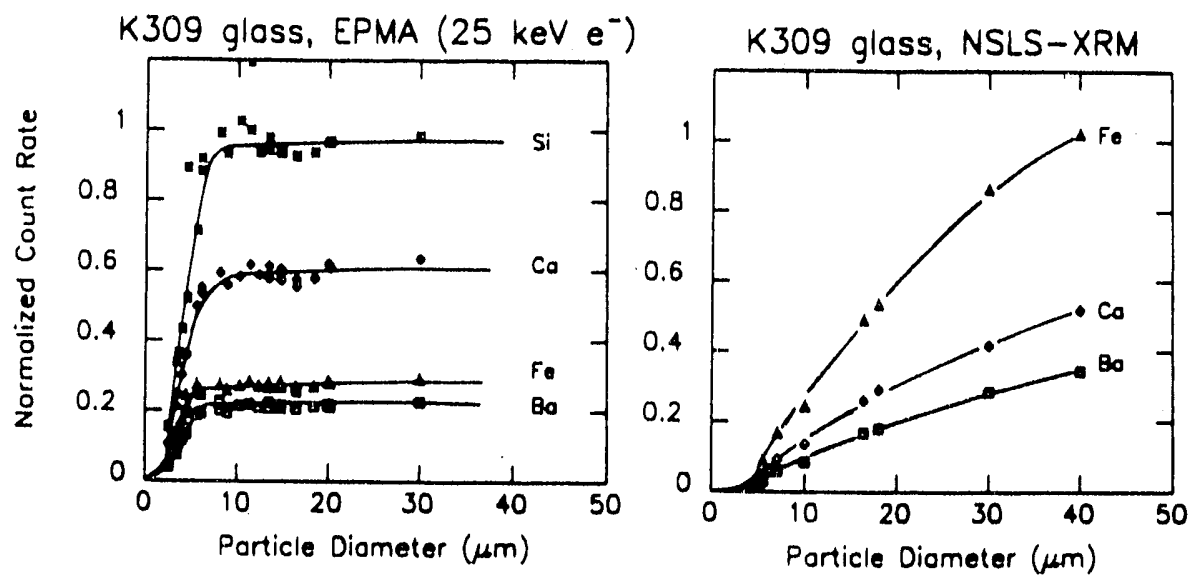

Fig. 4. Size-dependence of X-ray yields obtainable from $k 309$ microspheres using EPMA and the NSIS XRM. Solid curves intended to guide the eye.

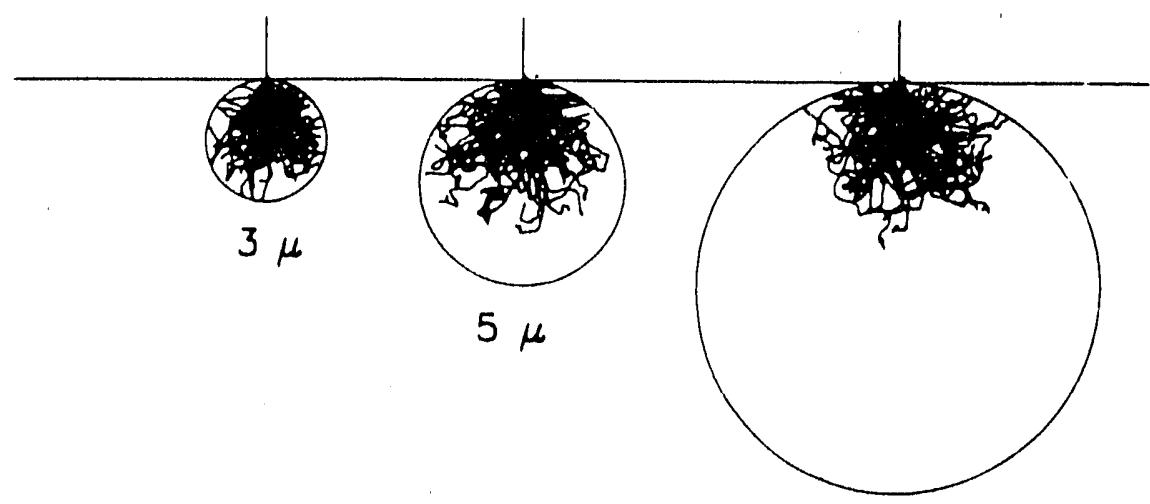

Particle Diameter $=10 \mu$

Eig. 5. Monte Carlo simulation of electron paths in $\mathrm{K} 309$ microspheres. 
Table 3. Mlnimum detectable amounts of $\mathrm{Ca}, \mathrm{Fe}, \mathrm{Ba}$ and $\mathrm{Pb}$ in $3.5 \mu \mathrm{m}$ radius microscopic particles.

\begin{tabular}{ccc}
\hline & \multicolumn{2}{c}{ Minimum Detectable Amount (pg) } \\
\cline { 2 - 3 } Element & NSLS XRM & EPMA \\
\hline Ca & 0.10 & 0.5 \\
Fe & 0.04 & 0.8 \\
Ba & 0.2 & 1.6 \\
$\mathrm{~Pb}$ & 0.4 & 1.1 \\
\hline
\end{tabular}

For the EPMA data, a rise in sensitivity is observed up to a particle diameter of around $5 \mu$. This behaviour can be explained by considering the size of the interaction volume of the primary electrons with the particles which is of the order of 5 to $7 \mu \mathrm{m}$ in the present case. As illustrated in Fig. 5, for particles with a radius larger than $2.5 \mu \mathrm{m}$, only a limited part of the particles is 'seen' by the electron beam, giving rise to a plateau in the size vs. intengity plots in Fig. 4.

In the case of the XRM data, in view of the much larger penetration depth of $\mathrm{X}$-rays in comparison with electrons, a less outspoken dependence of the X-ray yield with size can be observed. From Fig. 4 it follows that

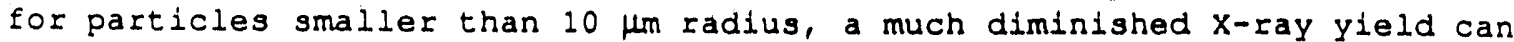
be expected, corresponding to MDL-values higher than those plotted in Fig. 3. This observation is important in view of the fact that the size distribution of e.g. ambient aerosols as collected on Nuclepore filters extends roughly from 0.1 to $10 \mathrm{\mu m}$. Whereas the NSIS XRM clearly features better relative MDL's in the case of particles which are larger than the beam dimensions (i.e., diameter > $10 \mu \mathrm{m}$ ), as shown in Table 3, for smaller. particles, and when absolute detectable amounts are considered, not so large differences between EPMA and XRM are observed. Indeed, when the particles become smaller than the $x$-ray beam size, not all of the available photon flux is used effectively, while in the case of EPMA, the total electron flux will still impinge on the particle. Nevertheless, for the smallest particles which could be analyzed, the NSLS XRM still is 5 to 10 times more sensitive than EPMA for resp. $\mathrm{Ca}$ and $\mathrm{Pb}$.

\section{CONCLUSIONS}

In this paper, the possibilities of employing $x$-ray based micro beam instruments for performing individual particle analygis were evaluated by analyzing glass microspheres of known composition. In contrast to EPMA detection limits in the 0.1 range, for the elements Ca to $\mathrm{z} n$, the NSLS XRM offers MD values at the ppm 1 to $10 \mathrm{ppm}$ level for counting times of 1000 sec/particle and for particles of ca. $20 \mu \mathrm{m}$. In the case of the SRS microprobe, in view of limitations in flux, MD values are a factor 10 higher in this range.

Considering the net count rate obtainable from microscopic particles at the NSLS, it can be concluded that performing individual particle analysis at the 10 to $100 \mathrm{ppm}$ level on coarse fraction aerosols (diameter $>5 \mathrm{\mu m}$ ) using the NSLS XRM is feasible employing relatively short measuring times (typically 50 to $100 \mathrm{sec}$ per particle) as required for individual analysis of large particle sets.

However, for (fine mode) particles whose diameter is smaller than the $x$-ray penetration depth and smaller than currently achievable beam sizes, a decrease in sensitivity with the third power of the particle diameter needs to be taken into consideration. In practise, analysis of the size fraction below $5 \mu \mathrm{m}$ is hampered by limitations in the optical visualisation system used on the $\mathrm{x}$-ray microprobes. 
The authors are indebted to $w$. Dorrine for assisting with the EPMA measurements. K.J. wants to thank the Belgian National science Fund for financial support. The research was supported in part by the US Department of Energy, office of Basic Energy sciences, Chemical Sciences Division, under Contract No. DE-AC02-76CH00016.M.R. wishes to thank the National Science Foundation (NSE) for support through grant No. EAR89-15699; S.S. acknowledges the support of the National Aeronautics and Space Administration (NASA) through grant No. NAG 9-106. The present research was also supported by the UK Science and Engineering Research Council (SERC) and the Netherlands organisation for advancement of Research (NWO) in connection with the agreement between SERC and NWO concerning the SRS.

\section{References.}

1. W. Maenhaut, in "Controle and Fate of Atmospheric Trace Metals," J.M. Pacyna, B. ottar, eds.. Kluwer Academic Publishers, New York $(1989)$.

2. A.L. Gray, in "Inorganic Mass Spectrometry", F. Adams, R. Gijbels, R. Van Grieken, eds.. Wiley, New York (1988).

3. D.L. Fox, Anal. Chem., 59:280R (1987).

4. A. Alian, B. Sansoni, J. Radioanal. Nucl. Chem., 89:191 (1985).

5. W. Maenhaut, Anal. Chim. Acta, 195:123 (1987).

6. R.E. Van Grieken, J.J. Labreque, in "Trace Analysign, Vol. 4, J.F. Lawrence, ed., Academic Press, New York (1985).

7. K.R. Spurny, (ed.), "Physical and Chemical Characterisation of

Individual Airborne Particles", Ellis Horwood, Chichester, UK (1985).
8. K. Janssens, W. Van Borm and P. Van Espen, NBS J. Res., 93:260 (1988).

9. S.H. Sie, C.G. Ryan, D.R. Cousens, W.L. Griffin, Nucl. Instr. Meth., B40/41:690 (1989).

10. R. Kaufmann, F. Hillenkamp, R. Wechsung, H.J. Helnen, M. Schürmann, in "Scanning Electron Microscopy", Vol. II, SEM InC., A.M.F. O'Hare, IL 60666, USA, (1979).

11. M. Cholewa, G. Bench, B. Kriby, G.F.J. Legge, Nucl. Ingtr. Meth. B, 1990, in press.

12. A.L. Hanson, H.W. Kraner, K.W. Jones, B.M. Gordon, R.E. Mills, J.R. Chen, IEEE Trans. Nucl. SCi., NS-30:1339 (1983).

13. K.W. Jones, B.M. Gordon, A.L. Hanson, J.B. Hastings, M.R. Howells, H.W. Kraner, J.R. Chen, Nucl. Instr. Meth., B3:225 (1984).

14. A.J.J. Bos, R.D. Vis, H. Verheul, M. Prins, S.T. Davies, D.K. Bowen, J. Makjanic, $V$. Valkovic, Nucl Instr. Meth., B3:232 (1984).

15. F. van Langeveide, R.D. Vis, Anal. Chem., accepted (1991).

16. V.B. Baryshev, G.N. Kulipanov, E.I. Zavtsev, Y.V. Terekhov, V.I. Kalyuzny, Nucl. Instr. Meth., A261:279 (1987).

17. S. Török, Z. Szökefalvi-Nagy, S. Sándor, V.B. Baryshev, K.V. Zolotarev, G.N. Kulipanov, Nucl. Instr. Meth., A282:499 (1989).

18. K.W. Jones, B.M. Gordon, Anal. Chem., 61:341A' (1989).

19. P. Ketelsen, A. Knöchel, W. Petersen, z. Anal. Chem., 323:867 (1986).

20. E. van Langeveide, D.K. Bowen, G.H.J. Tros, R.D. Vis, A. Huizing, DKG de Boer, Nucl. Instr. Meth., A292:719 (1990).

21. J.H. Underwood, A.C. Thompson, Y. Wu, R.D. Giauque, Nucl. Instr. Meth., A266:296 (1988).

22. Y. Goshi, S. Aoki, A. Iida, S. Hayakawa, H. Yamaij, K. Sakurai, Jpn. J. Appl. Phys., $26:$ Li260 (1987).

23. J.A. Small, K.F.J.Heinrich, C.E. Fiori, R.L. Myklebust, D.E. Newbury, M.F. Dilmore, in "Scanning Electron Microscopy", Vol. 1, SEM Inc, AMF o'Hare, IL, USA (1987).

24. R.D.Vis, Fres. J.Anai. Chem., $337: 622$ (1990).

25. R. Jenking, Spectrochimica Acta, $37: 207$ (1982).

\section{DISCLAIMER}

This report was prepared as an account of work sponsored by an agency of the United States Government. Neither the United States Government nor any agency thereof, nor any of their employees, makes any warranty, express or implied, or assumes any legal liability or responsibility for the accuracy, completeness, or usefulness of any information, apparatus, product, or process disclosed, or represents that its use would not infringe privately owned rights. Reference herein to any specific commercial product, process, or service by trade name, trademark, manufacturer, or otherwise does not necessarily constitute or imply its endorsement, recommendation, or favoring by the United States Government or any agency thereof. The views and opinions of authors expressed herein do not necessarily state or reflect those of the United States Government or any agency thereof. 

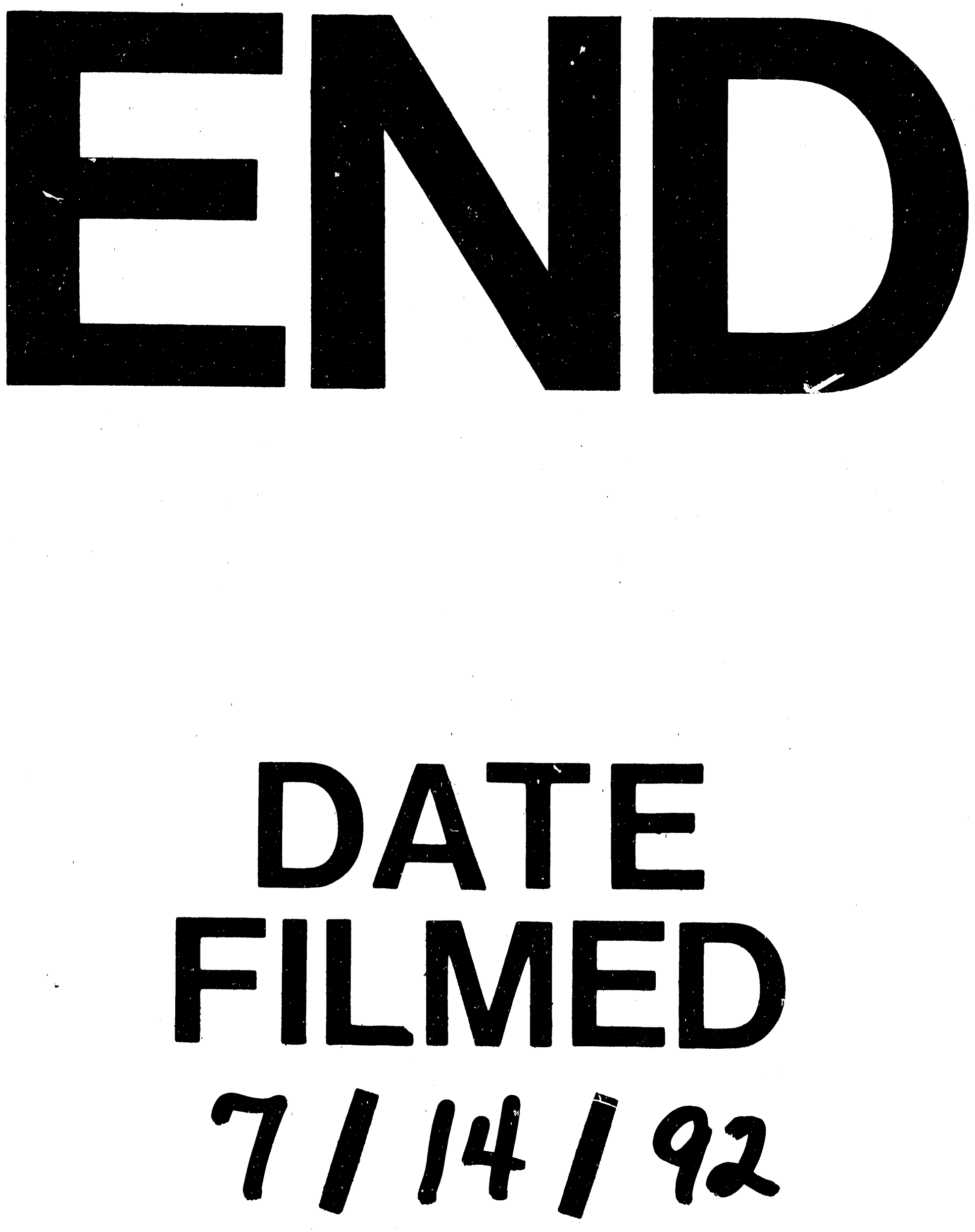
